\title{
Functional outcomes of reverse distal femoral locking plate in the extra capsular fractures of proximal femur
}

\author{
Jaspreet Singh ${ }^{1}$, Harpal Singh Selhi ${ }^{2}$, Rahul Gupta ${ }^{2}$, Gurleen Kaur ${ }^{3 *}$
}

\author{
Department of Orthopaedics, ${ }^{1}$ Civil Hospital, Rajpura, ${ }^{2}$ Dayanand Medical College and Hospital, Ludhiana, Punjab, \\ India \\ ${ }^{3}$ Department of Pharmacology, Adesh Medical College and Hospital, Shahabad (M), Haryana, India
}

Received: 16 February 2019

Revised: 08 March 2019

Accepted: 09 March 2019

\author{
*Correspondence: \\ Dr. Gurleen Kaur, \\ E-mail: drgurleen04@gmail.com
}

Copyright: () the author(s), publisher and licensee Medip Academy. This is an open-access article distributed under the terms of the Creative Commons Attribution Non-Commercial License, which permits unrestricted non-commercial use, distribution, and reproduction in any medium, provided the original work is properly cited.

\begin{abstract}
Background: The optimal management of unstable proximal femoral fractures is controversial. In this prospective study, the functional outcomes of reverse distal femoral locking plate for the treatment of comminuted unstable proximal femoral fractures were assessed. Objectives were to study the functional outcomes of reverse locking plate in extra-capsular fractures of the proximal femur, with respect to quality of reduction, time to bony union, mobility achieved, complications of the procedure, secondary procedures performed (if any) and delayed complications like implant breakage, delayed union, non-union.

Methods: 17 patients with unstable proximal femoral fractures were assessed and managed with reverse distal femur plates, and evaluated with X-ray, physical examination, Palmer and Parker mobility score.

Results: Union was achieved in all the patients, with average time to union $6.43 \pm 1.18$ months (range 3-12 months). There was one loosening of implant and wound breakdown, which was managed conservatively. One case of loosening of proximal screws was there, but the fracture united in 9 months with some varus angulation. Superficial infection occurred in one patient, which healed after debridement and IV antibiotics.

Conclusions: Taking into consideration the simple surgical technique, good healing rate and minimum complications, it is strongly recommended to use reverse locked distal femoral plates for the management of proximal femoral fractures and further in lean patients, sum-muscular MIPPO should be attempted.
\end{abstract}

Keywords: Unstable proximal femoral fractures, Extra-capsular fracture

\section{INTRODUCTION}

Hip fractures are the most devastating injuries an all age groups, with $90 \%$ of hip fractures in $>50$ years' age group. Due to increased general life expectancy of population and incidence of road traffic accidents, there is increased incidence of fractures of proximal femur. ${ }^{1}$ These fractures are associated with substantial morbidity and mortality in elderly patients, with $15-20 \%$ mortality within 1 year of fracture. ${ }^{2}$ Sub-trochanteric fractures (account for $10 \%$ of proximal femur fractures) have a bimodal distribution, in 20-40 and $>60$ years of age. ${ }^{3}$

Extra-capsular fractures (Inter-trochanteric and subtrochanteric fractures) primarily involve cortical and compact cancellous bone. The complex stress configuration of this region and its nonhomogeneous osseous structure results in fractures along the path of least resistance through the proximal femur. ${ }^{3}$ 
Every proximal femur fracture must be assessed individually and it will be irrational to establish fixed routines of treatment. Numerous difficulties may arise in the management of unstable intertrochanteric fractures because of the degree of osteoporosis, reverse obliquity of the fracture line, comminution on the medial side. ${ }^{4}$

The use of proximal femur nail allows a faster postoperative restoration of walking ability, when compared with the dynamic hip screw. ${ }^{5}$ The intra-medullary locked nailing was technically demanding in proximal femur fractures and may result in iatrogenic propagation of the fracture with the risk of varus malunion. ${ }^{6}$

The main advantages gained after use of reverse distal femoral locking compression plate are the plate and screw form a stable construct and the stability of the fracture depends on the stiffness of the construct. There is improved stability in multi-fragmentary compressed fractures with loss of medial/lateral buttress or bone loss. Moreover, the locked screw/plate interface provides fixed angle stability, which avoids subsidence in the metaphyseal region. There is no need to precisely contour the plate. Also, there is improved biology for healing. Locked internal fixators do not compress the periosteal blood supply, thereby causing less interference of the fracture haematoma and fracture healing. There is improved fixation and biology lead to better clinical outcome and faster healing. This leads to better fixation in osteoporotic bone. ${ }^{7-9}$

In unstable proximal femur fractures that were difficult to nail and were therefore, were managed with reverse distal femoral locking plate was observed that the complications like pain, delayed union were less frequent. $^{4}$

Hip or proximal femur fractures have been a common injury which has an increasing incidence with ageing population. Within the developed countries, it appears that the age specific incidence of hip fractures which was increasing, is flattening out or even static now. Less developed countries were just beginning to see this dramatic increase in hip fractures. ${ }^{1}$ High incidence of complications after surgical treatment has led to development of intra-medullary and extra-medullary implants.

The study was planned to evaluate and analyze the functional outcomes of reverse distal femoral locking plate in extra-capsular fractures of the proximal femur (inter-trochanteric and sub-trochanteric), with respect to quality of reduction, time to bony union, mobility achieved, complications of the procedure, secondary procedures performed (if any) and delayed complications like implant breakage, delayed union, non-union.

\section{METHODS}

After approval from institutional ethics committee, the prospective study was done in patients admitted to the
Department of Orthopaedics, DMCH, Ludhiana, Punjab from June 2010 to June 2012. Informed consent was taken from all the patients. The patients included in the study had extra-capsular fracture of proximal femur with one or more of the following: unstable fracture pattern, bowed femur, deformed femur, short skeleton, narrow femoral canal (diameter $<8 \mathrm{~mm}$ ), open fracture presenting within 24 hours.

\section{Pre-operative regimens}

All patients of proximal femur fracture coming to Emergency were evaluated and resuscitated. After the initial resuscitation, all patients were assessed in details for any other injuries and medical ailments and managed accordingly. Pre-operative investigations and preanaesthetic checkup was done, informed consent taken and the patient was taken up for surgery.

\section{Surgical technique}

The surgery was conducted under anesthesia, with the patient in the supine position on radiolucent table with traction attachment. Traction was applied to the injured leg by a padded holder on the foot. A padded perineal post was used for counter traction. The unaffected limb was placed in hip abduction and knee flexion. An accurate closed reduction was done under fluoroscopic control and maintained by traction with a boot.

The reverse locking plates are separately available for right and left side and in various lengths. The reverse locking plate is pre-shaped to account for the anterior bow of the shaft zone of the femur. A contralateral side distal femoral locking plate was used 'upside down' for stabilization of the proximal femur fracture. Depending on the patient's body habitus, a $2.5-8 \mathrm{~cm}$ incision was given just proximal to the greater trochanter, and taken to the level of the fascia. Submuscular plane was developed under vastus lateralis and reverse locking plate was inserted submuscularly across the fracture site while maintaining slight contact with the bone under image guidance. In cases where closed reduction fails, open reduction was carried out by extending down incision over the middle of greater trochanter to the lateral side of the thigh over lateral aspect of femur in standard manner. The length of the incision varied with the requirements of the surgery. After ensuring an optimal placement of the plate on the femur, it was temporarily fixed to the bone with Kirschner wire via proximal and distal connected trocars. In closed procedures, position of the reverse locking plate was checked again radiographically before inserting. Thereafter first non-locking screw was inserted and then locking head screws using the appropriate drill bits were inserted. To ensure secure fixation, four to six screws were placed into the proximal component of the fracture and three to four screws were placed into the distal component of the fracture. Optimal placement and screw length was ensured under fluoroscopy in two 
planes. Finally, the incisions in the vastus fascia were closed with or without drainage, in the standard fashion.

Post-operatively, non-weight-bearing toe-touch ambulation was started as soon as pain was bearable. Check X-rays were done at regular intervals. More than $50 \%$ visible bridging callus across the fracture on plain radiograph was regarded as indicator of fracture healing. Neck shaft angle was measured post operatively and at follow-up visits. Complications like non-union, shortening, infection were recorded.

The data collected was analyzed using Microsoft Excel 2015. Mean and standard deviation was calculated and unpaired t-test applied to the score (mobility score). $\mathrm{P}<0.05$ was taken a significant.

\section{RESULTS}

17 cases of proximal femur fracture were enrolled in the study. In our study, there were 6 sub-trochanteric and 11 inter-trochanteric fractures. 4 out of 6 sub-trochanteric fractures were under 40 years age and 9 out of 11 intertrochanteric fractures were over 40 years age. There were 14 male and 3 female patients. The age distribution of the patients is shown in Figure 1.

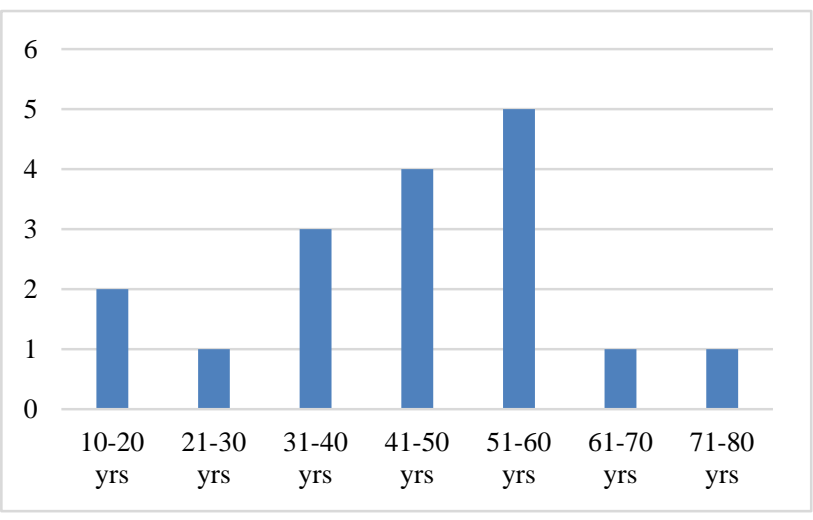

Figure 1: Age distribution of patients.

In 8 out of 17 patients, the duration of surgery was more than 2 hours. The mean duration of surgery in intertrochanteric fractures was $135 \pm 24.8$ minutes and for subtrochanteric fractures was $115 \pm 22.8$ minutes.
15 out of 17 patients attended follow-up for a minimum of 1 year. Partial weight bearing walking was started at 2 months in 6 patients, 3 months in 4 patients and at more than 4 months in 3 patients. Full weight bearing walking was started at 5 months in 11 patients, at 9 months in 3 patients and at 1 year in 1 patient, as explained in Figure 2.

One patient had early infection, which was managed with debridement and IV antibiotics. Early loss of fixation and wound breakdown was seen in one patient, which was managed with IV antibiotics and skeletal traction. Hip flexion was $>90^{\circ}$ in 11 patients, hip abduction was $>20^{\circ}$ in 12 patients. Internal rotation was $>15^{\circ}$ in 9 patients and external rotation was $>15^{\circ}$ in 13 patients.

One patient, who had loosening of the screw and persistent pain on lateral thigh, achieved bony union after 9 months. One patient had shortening of about $2 \mathrm{~cm}$ with varus angulation due to ipsilateral shaft femur tibia fracture and early weight bearing. This patient had stiffness of the knee joint due to retrograde intramedullary nailing for shaft femur and nailing for tibia. One more patient had shortening of $<1 \mathrm{~cm}$ along with varus malunion. Stiffness of hip was noted in one patient as the patient had associated secondary degeneration of bilateral hip joints, which required rigorous physiotherapy. The delayed complications are described in Table 1.

Table 1: Delayed complications.

\begin{tabular}{|ll|}
\hline Delayed complications & No. of patients \\
\hline Delayed infection & 1 \\
\hline Shortening & 2 \\
\hline Loosening of screws & 1 \\
\hline Stiffness of hip & 1 \\
\hline Knee stiffness & 1 \\
\hline Delayed union & 5 \\
\hline Varus angulation & 2 \\
\hline Implant breakage & 0 \\
\hline
\end{tabular}

The mobility was evaluated at the last follow-up by the Palmer and Parker Mobility score, which is shown in Table 2.

Table 2: Distribution of subjects according to Palmer and Parker mobility score.

\begin{tabular}{|lllllll|}
\hline \multirow{2}{*}{ Functional results } & \multicolumn{2}{l}{ Subtrochanteric fractures } & \multicolumn{2}{l|}{ Intertrochanteric fractures } & \multicolumn{2}{c|}{ Total } \\
& Number $(\mathbf{n})$ & Age $(\boldsymbol{\%})$ & Number $(\mathbf{n})$ & Age $(\boldsymbol{\%})$ & Number $(\mathbf{n})$ & Age $(\boldsymbol{\%})$ \\
\hline $\mathbf{9}$ & 5 & 83.33 & 7 & 63.64 & 12 & 70.59 \\
\hline $\mathbf{6 - 8}$ & 1 & 16.67 & 3 & 27.27 & 4 & 23.53 \\
\hline $\mathbf{3 - 5}$ & 0 & 0.00 & 0 & 0.00 & 0 & 0.00 \\
\hline$<3$ & 0 & 0.00 & 0 & 0.00 & 0 & 0.00 \\
\hline Expired & 1 & 0.00 & 1 & 9.99 & 1 & 5.88 \\
\hline
\end{tabular}

$\mathrm{P}=0.046$. This difference in distribution was statistically significant. 


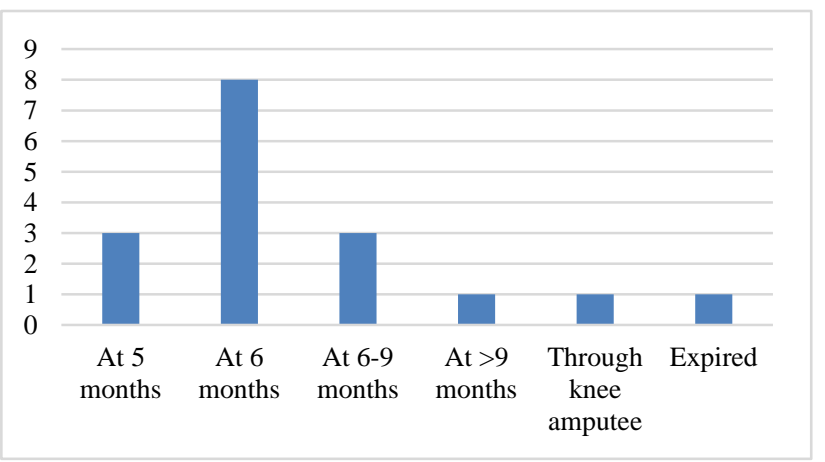

Figure 2: Distribution according to full weight bearing walking.

\section{DISCUSSION}

While there are several methods for fixation of hip surgery, the optimal method is unclear because of high rate of complications in all the methods. Fixation of hip fracture with plating is a good method for intertrochanteric femur. But intramedullary nailing is becoming popular. So we reviewed the literature to look for new recommendations for hip fracture fixation.

Kummer et al compared intramedullary hip screw system and extra-medullary screw plate system. They found similar stability for fixation of two part and three part sub-trochanteric fractures. ${ }^{10}$

Simmermacher et al observed that the intramedullary devices for the treatment of unstable trochanteric femoral fractures were technically demanding and had considerable failure rate. ${ }^{11}$ Kish et al concluded that PFN (proximal femoral nail) allowed full weight bearing immediately after surgery and it appears advantageous compared the DHS (dynamic hip screw). ${ }^{12}$ Jeffrey et al noted that the patients with intra-medullary nailing had more procedure related complications. ${ }^{13}$ Yao et al compared reverse less invasive stabilization system (LISS) plating to intramedullary nailing and concluded that reverse LISS plating be reserved for rapid fixation and damage control in poly trauma patients. ${ }^{14}$

Ning et al concluded that LISS plating may be indicated for patients with very severe osteoporosis. ${ }^{15}$ Lewis et al, Ozkaya et al, Zhang et al concluded that reverse LISS plating for intertrochanteric hip fractures is a safe and alternative method. ${ }^{6,16,17}$

In our study, the average duration of surgery was $127 \pm 25$ minutes, which is longer than that reported in others (average 60-70 minutes). ${ }^{4,15}$ However in both the studies, distal targeting system was used. In our study, most of the fractures were stabilized by open method, which had no distal targeting device.

Chang et al reported a series of 20 patients had an average operating time of 115 minutes which is almost similar to our study. ${ }^{18}$ The variation in duration of surgery can be attributed to learning curve, implant design, operation room set-up and familiarity of staff with the procedure.

Partial weight bearing (PWB) walking was started after clinical and radiological progress of the fracture. French et al started PWB walking in their patients when there was bridging callus in one view of the follow-up Xrays. ${ }^{19}$ Similar protocols of physiotherapy were found to be followed by other authors. ${ }^{4,6}$

According to Parker mobility criteria, 12 patients scored 9 points and 4 patients had 6 points at final assessment performed at 1 year after fracture fixation. Our mobility score was comparable with Ning et al (average mobility score 8.25 vs. $8.11 \pm 0.8$ ) and slightly lower as compared to Ching et al ( 8.55 vs. 8.25$)$ as this study had no patient with ipsilateral amputation at the final follow-up. ${ }^{4,15}$ On excluding this patient, our average mobility score was 8.4 , which is more nearer to that reported by Ching et al. ${ }^{4}$

The average post-operative neck shaft angle was $130.2 \pm 6.38$ degrees, which is less than as compared to other authors. ${ }^{4,18}$ This could be due to excessively comminuted fractures and varus malunion in two patients. The mean time to fracture union was $6.43 \pm 1.18$ months, which is similar to 6-6.5 months as observed in other studies. $^{15,6}$

\section{Complications}

One patient had superficial surgical site infection, which healed with IV antibiotics, debridement and dressings. Another patient had an infection leading to implant loosening and loss of reduction. The infection rate was higher as compared to other studies. ${ }^{4,18}$ This could be attributed to their poor nutritional status.

Shortening of $2 \mathrm{~cm}$ and varus malunion was observed in one patient. This was due to lack of compliance by the patient and early mobilization. No screw breakage was reported. This is comparable to Ching et al. ${ }^{4}$

One patient had screw loosening but fracture union was achieved in 6 months without any secondary procedures. No implant breakage was observed in our study. No medical complications were noted perioperatively in this study.

Though all the fractures in our study healed, it is hard to say that reverse distal locking plate is substantial enough in highly unstable fractures since the small sample of our study could prevent us from observing more complications. At last, we conclude that the reverse distal femur locking plate is a good alternative to stabilize the unstable proximal fractures especially when used in conjunction with careful preoperative planning, meticulous intra-operative handling of soft tissues and 
active participation of the patients in rehabilitation program.

\section{CONCLUSION}

From this study, we conclude that unstable fractures unite satisfactorily within reasonable period of time by use of reverse distal femur locking plate. There were fewer complications, early mobilization and high patient satisfaction. Reverse distal femoral locking plate is a treatment option that needs to be evaluated further in order to recommend this surgery for specific subset of patients with hip fractures. In initial studies, the results have been encouraging and patient satisfaction achieved. Further studies to look into the biomechanical aspects of reverse distal femur locking plate and the clinical outcome of the surgery should be done. This will allow well formulated indications and contra-indications for the surgery.

Funding: No funding sources

Conflict of interest: None declared

Ethical approval: The study was approved by the institutional ethics committee

\section{REFERENCES}

1. Zuckerman JD. Hip fracture. $\mathrm{N}$ Engl $\mathrm{J}$ Med. 1996;334(23):1519-25.

2. Evans PJ, McGrory BJ. Fractures of the proximal femur. Hospital Physician. 2002;30-8.

3. Austin CA, Lawson PJ, Gibson R, Philp I. Proximal femoral fracture: achievements and prospects. Age Ageing. 1998;27:667-70.

4. Ma CH, Tu YK, Yu SW, Yen CY, Yeh JH, Wu CH. Reverse LISS plates for unstable proximal femoral fractures. Injury. 2010;41:827-33.

5. Panjarinen J, Lindahl J, Michelsson O, Savolainen V, Hirvensalo E. Pertrochanteric femoral fractures treated with a dynamic hip screw or a proximal femoral nail. J bone Joint Surg (Br). 2005;87:76-81.

6. Zhang CQ, Sun Y, Jin DX, Yao C, Chen SB, Zeng BF. Reverse LISS plating for intertrochanteric Hip Fractures in elderly patients. BMC Musculoskelet Disord. 2010;11;166.

7. Smith WR, Ziran BH, Anglen JO, Stahel PF. Locking plates: tips and Tricks. J Bone Joint Surg Am. 2007;89:2298-307.

8. Sommer C, Gautier E, Muller M, Helfet DL, Wagner M. First Clinical results of the locking Compression Plate (LCP). Injury. 2003;34(12):4354.

9. Wagner M. General principles for the clinical use of the LCP. Injury. 2003;34(2):31-42.
10. Kummer FJ, Olsson O, Pearlman CA, Cedar L, Larsson S, Koval KJ. Intramedullary versus extramedullary fixation of subtrochanteric fractures. A biomechanical study. Acta Orthop Scand. 1998;69(6):580-4.

11. Simmermacher RK, Bosch AM, Van der WC. The AO/ASIF-proximal femoral nail (PFN): A new device for the treatment of unstable proximal femoral fractures. Injury. 1999;30:327-32.

12. Kish B, Sapir O, Carmel A, Regev A, Masrawa S. Full weight bearing after unstable per and subtrochanteric fracture using proximal femur nail. J Bone Joint Surg Br. 2001;83(3):289.

13. Anglen JO, Weinstein JN. Nail or plate Fixation of Intertrochanteric Hip Fractures: Changing Pattern of Practice. A Review of the American Board of Orthopaedic Surgery Database. J Bone Joint Surg Am. 2008;90:700-7.

14. Yao C, Zhang CQ, Jin DX, Chen YF. Early results of reverse less invasive stabilization system plating in treating elderly intertrochanteric fractures: a prospective study compared to proximal femoral nail. Chin Med J (Engl). 2011;124:2150-7.

15. Ning H, Gui XS, Zeng CL, Guo FL, Qing YL, Qing $\mathrm{HH}$, Xin W. Comparison of proximal femoral nail antirotation blade and reverse less invasive stabilization system-distal femur systems in the treatment of proximal femoral fractures. Orthopaedic Sur. 2011;3(1):7-13.

16. Lewis JRP, Ashcroft GP. Reverse LISS plating for proximal segmental femoral fractures in the polytrauma patient: a case report. Injury. 2007;38(2):235-9.

17. Ozkaya U, Bilgili F, Kilic, Parmaksizoglu AS, Kabukcuoglu Y. Minimally invasive management of unstable proximal femoral extracapsular fractures using reverse LISS femoral locking plates. Hip Int. 2009;19(2):141-7.

18. Oh CW, Kim JJ, Byun YS, Oh JK, Kim JW, Kim SY, Park BC, Lee HJ. Minimally invasive plate osteosynthesis of subtrochanteric femur fractures with a locking plate: a prospective series of 20 fractures. Arch Orthop Trauma Surg. 2009;700-21.

19. French BG, Tornetta P. Use of interlocked cephalomedullary nail for subtrochanteric fracture stabilization. Clin Orthop Relat Res. 1998;(348):95100 .

Cite this article as: Singh J, Selhi HS, Gupta R, Kaur G. Functional outcomes of reverse distal femoral locking plate in the extra capsular fractures of proximal femur. Int J Res Orthop 2019;5:417-21. 